\title{
Mediators of Mast Cells in Bullous Pemphigoid and Dermatitis Herpetiformis
}

\author{
Agnieszka Zebrowska, ${ }^{1}$ Malgorzata Wagrowska-Danilewicz, ${ }^{2}$ \\ Marian Danilewicz, ${ }^{2}$ Olga Stasikowska-Kanicka, ${ }^{2}$ Lilianna Kulczycka-Siennicka, ${ }^{1}$ \\ Anna Wozniacka, ${ }^{1}$ and Elzbieta Waszczykowska ${ }^{1}$ \\ ${ }^{1}$ Department of Dermatology and Venereology, Medical University of Lodz, Plac Hallera 1, 90-497 Lodz, Poland \\ ${ }^{2}$ Laboratory of Nephropathology of Medical University of Lodz, Pomorska 251, 92-213 Lodz, Poland \\ Correspondence should be addressed to Agnieszka Zebrowska; zebrowskaaga@wp.pl
}

Received 29 June 2014; Revised 1 October 2014; Accepted 3 October 2014; Published 21 October 2014

Academic Editor: Magdalena Klink

Copyright (C) 2014 Agnieszka Zebrowska et al. This is an open access article distributed under the Creative Commons Attribution License, which permits unrestricted use, distribution, and reproduction in any medium, provided the original work is properly cited.

\begin{abstract}
Bullous pemphigoid (BP) and dermatitis herpetiformis (DH) are skin diseases associated with inflammation. However, few findings exist concerning the role of mast cells in autoimmune blistering disease. Skin biopsies were taken from $27 \mathrm{BP}$ and $14 \mathrm{DH}$ patients, as well as 20 healthy individuals. Immunohistochemistry was used to identify the localization and mast cell expression of TNF $\alpha$ and MMP9 in skin lesions and perilesional skin. The serum concentrations of TNF $\alpha$, MMP9, chymase, tryptase, PAF, and IL-4 were measured by immunoassay. TNF $\alpha$ and MMP9 expression in the epidermis and in inflammatory influxed cells in the dermis was detected in skin biopsies from patients. Although these mediators were found to be expressed in the perilesional skin of all patients, the level was much lower than that in lesional skin. Increased serum PAF levels were observed in BP patients. Mast cells may play an essential role in activating inflammation, which ultimately contributes to the tissue damage observed in $\mathrm{BP}$ and $\mathrm{DH}$. Our findings suggest that differences in the pattern of cytokine expression directly contribute to variations in cellular infiltration in $\mathrm{DH}$ and $\mathrm{BP}$.
\end{abstract}

\section{Introduction}

Dermatitis herpetiformis (DH) is one of the subepidermal autoimmune bullous diseases, which is characterized by skin and intestinal lesions. Skin lesions include polymorphic eruption accompanied by severe pruritus. Intestinal lesions are characterized by atrophy of intestinal villi resulting from immunological process [1]. Diagnosis of DH is established on the basis of a direct immunofluorescence test (DIF) revealing granular deposits of IgA in the papillae and the presence of circulating IgA antibodies directed against the endomysium and/or tissue and epidermal transglutaminase (tTG, eTG) $[2,3]$. Skin lesions in $\mathrm{DH}$ are histologically characterized by neutrophilic infiltrates leading to destruction of basement membrane zone (BMZ) proteins and anchoring fibers and blister formation [4-6].

Bullous pemphigoid (BP) is a blistering disease characterized by inflammatory infiltrate in the dermis and the presence of IgG and C3 deposits along the BMZ and circulating IgG autoantibodies. Autoantibodies bound to autoantigens, the glycoproteins BPAG1 $(230 \mathrm{kD})$ and BPAG2 $(180 \mathrm{kD})$, localized in the basement membrane of the epidermis activate a series of immunological and enzymatic phenomena leading to the destruction of basement membrane components and the formation of blisters, as observed in $\mathrm{DH}[7,8]$.

In the dermis, inflammatory infiltrates formed by eosinophils and neutrophils and bound in vivo deposits, can be observed along the basement membrane or at the top of papillae. Ultrastructural studies have also confirmed the presence of intensive inflammatory infiltrates at the dermoepidermal junction, as well as destruction of hemidesmosomes and components of the extracellular matrix [9].

Infiltrate formation is preceded by early accumulation of leukocytes, depending on the activity of adhesion molecules. The binding of autoantibodies leads to the activation of keratinocytes, which release cytokines, as well as the activation of 
metalloproteinases and the $\mathrm{C} 5$ component of the complement $[10,11]$. Many mediators are important chemoattractants for both eosinophils and neutrophils [12, 13].

Mast cells are a source of many mediators, cytokines, and enzymes which may affect the course of inflammation in the skin in different ways. One mediator which plays a very important role in the development skin lesions in autoimmune skin diseases is tumor necrosis factor $\alpha$ (TNF $\alpha)$. Other cytokines derived from mast cells also appear to be involved in the inflammatory process in skin. In the course of BP and $\mathrm{DH}$, an important role is played by mast cell mediators such as histamine, tryptase, and chymase. Evidence suggests that metalloproteinase (MMP9 in particular), leukotrienes (LT), platelet activating factor (PAF), and heparin derived from mast cells play a role in the inflammatory process involved in blister formation [14]. Recent data on the role of cytokines and mediators from mast cells in blister formation should be taken into account in the planning of new methods for treating these diseases. The aim of the study was to evaluate the expression of these markers of mast cells in skin lesions and the perilesional area, as well as in the serum of patients with $\mathrm{DH}$ and $\mathrm{BP}$.

\section{Materials and Methods}

2.1. Patients. The study included 61 persons: 27 untreated patients with BP (range: 58 to 84 years, average: 68.5 ) and 14 with $\mathrm{DH}$ (range: 18 to 70 years, average: 49.8 ) in an active stage of the disease. The control group comprised 20 healthy individuals in total. The mean age of control group number 1 (10 patients), for BP patients, was 71.6 years (range 50 to 80 years) while the mean age of control group number 2 (10 patients), DH patients, was 42 years (range 19 to 49 years). The control groups consisted of unrelated volunteers matched for sex and age.

In all DH cases, histological examination revealed perivascular neutrophilic infiltrates, the presence of Pierrard's abscesses, and small subepidermal blisters. In most samples, large unilocular blisters displaying multiple neutrophilic papillary microabscesses were found. All histopathological findings according to Ackerman were fully developed [15]. Direct immunofluorescence tests revealed the presence of granular deposits of IgA in skin papillae and all indirect immunofluorescence tests were positive for IgAEmA (Oesophagus monkey IgAEmA, Medizinische Labordiagnostica). Immunoassay (Celikey, Pharmacia \& Upjohn) revealed the presence of anti-tissue transglutaminase antibodies in $8 / 14$ cases. Diagnosis of DH was established based on clinical presentation and results of histological and immunological examination.

Twenty-seven patients ( 16 women, 11 men; mean age 68.5 years; range: 58-84) with $\mathrm{BP}$ were included in the study. Pemphigoid was diagnosed based on clinical picture and histological and immunological findings. The patients were at an active stage of the disease; 22 of the 27 patients presented with skin blisters, vesicles, and itching papules, whereas the rest had only small vesicles and urticarial papules. In all cases, the histopathology findings were fully developed according to Ackerman et al. [15]. In all patients, direct immunofluorescence assay revealed IgG/C3 linear deposits along the BMZ. In the salt split test, deposits were observed in the epidermal part of the blister. Indirect immunofluorescence assay revealed circulating IgG antibodies to be present in all patients. According to ELISA, anti-Nc16 autoantibodies (MBL, Nagoya, Japan) were present in the serum of 21 out of 27 patients. The clinical diagnosis was supported by typical histological features of BP, including the presence of neutrophilic infiltrates, eosinophils, and lymphocytes (as well as subepidermal blisters in 22 cases).

All the patients gave their informed written consent before entering the study. The study protocol (RNN/132/07/ $\mathrm{KB}$ ) was approved by the Local Ethical Committee of the Medical University of Lodz.

Tissue Specimens. The biopsies were taken from the skin of the buttock or trunk before administration of any (topical or systemic) treatment. Skin lesions lasted between 2 weeks and 4 months. Biopsy specimens were taken from skin of the buttock from healthy volunteers.

2.2. Immunohistochemistry. Paraffin-embedded sections, 3$4 \mu \mathrm{m}$ thick, were used for routine H\&E staining and for immunoperoxidase immunohistochemical examination with the DAKO EnVision detection system. The following primary monoclonal antibodies were used: anti-TNF $\alpha$ (R\&D, UK) and matrix metalloproteinase 9 (MMP9) (Novocastra).

For immunohistochemistry, the paraffin-embedded sections were placed on adhesive plates and dried at $56^{\circ} \mathrm{C}$ for 24 hours and were later deparaffinated in a series of xylenes and alcohols with decreasing concentrations. The activity of endogenous peroxidase was inhibited with $3 \%$ hydrogen peroxide solution in methanol for 5 minutes.

In order to retrieve the antigenicity of tissues and allow them to react with antibodies, specific procedures were used for each tested antibody, according to the manufacturer's instructions. After incubation with diluted antibodies for 60 minutes at room temperature, they were washed with Tris buffer twice. DAKO EnVision double-step visualization system was then applied in order to visualize the antigenantibody reaction. In the case of a positive immunohistochemical reaction, cellular nuclei were stained with Meyer haematoxylin for 2 minutes. After dehydration and processing through a series of acetones and xylenes, the sections were fixed in Canadian balm.

2.3. Semiquantitative Analysis. In each specimen, the staining intensity of MMP9 and TNF $\alpha$ in inflammatory infiltrates was recorded by two independent observers in 7-10 adjacent high power fields. They were graded from 0 (staining not detectable), 1 (minimal immunostaining in some cells), 2 (weak immunostaining intensity in all cells), and 3 (strong staining in all cells). The mean grade was calculated by averaging the grades assigned by the two authors and approximating the arithmetical mean to the nearest unity.

2.4. Morphometry. Histological morphometry of MMP9 and $\mathrm{TNF} \alpha$ immunoexpression by epithelial and inflammatory 
cells was performed by using an image analysis system. The hardware comprised a PC with Indeo Fast card (frame grabber, true colour, real time) (Indeo, Taiwan) and colour video camera (Panasonic, Japan) linked to a Jenaval microscope (Carl Zeiss, Germany). The software used was MultiScan 8.08 (Computer Scanning Systems, Poland). The following values were calculated: the number of objects (semiautomatic function) and the surface area of the structure based on a stereological grid, with a regulated number of points.

The percentage of immunopositive inflammatory cells was estimated by counting 100-120 inflammatory cells in 710 adjacent high power fields on each slide using the semiautomatic function. The staining in the epithelial cells was measured using the point-counting method, based on Weibel [16]. The point spacing was $16 \mu \mathrm{m}$. The total number of points in the grid was 169 , and total area was 36864 sq. $\mu \mathrm{m}$. Using this grid, 7-10 randomly selected adjacent fields of the epithelium were investigated. The percentage of positive staining was calculated as the percentage of the number of points overlying positive areas with regard to the total number of points counted.

2.5. Statistical Methods. Median levels of TNF and MMP9 for patients with BP and DH in lesions (L) and surrounding (S) were compared using the nonparametric Mann-Whitney $U$ test. Results were considered statistically significant if $P<$ 0.05 .

2.6. Serum Chemokine Levels. In order to determine the concentrations of the examined protein in the serum, the enzyme-linked immunoassay method was used: chymase: ELISA Kit for Human Chymase 1 Mast Cell (Uscn Life Science), tryptase: ELISA Kit for Human Tryptase (Uscn Life Science), TNF $\alpha$ : Human TNF $\alpha$ ELISA Kit (Gen-Probe Diaclone), IL-4: Human IL-4 ELISA Kit (Gen-Probe Diaclone), PAF: ELISA Kit for Human Platelet Activating Factor (PAF) (Uscn Life Science), and MMP9 (Quantikine, R\&D Systems).

Chymase, tryptase, TNF $\alpha$, PAF, MMP9, and IL-4 levels were measured in serum in all patients and healthy controls undergoing skin biopsy. Samples of $5 \mathrm{cc}$ venous blood were drawn from the ulnar vein, and, after centrifugation, the serum was stored at $-20^{\circ} \mathrm{C}$ for an immunoassay.

2.7. Statistical Methods. All data was presented as median and range. Nonparametric Kruskal-Wallis analysis was performed followed by a median test. Significance at $P<0.05$ was taken as statistically significant. Statistical analysis was carried out using Statistica 10 software (Statsoft Polska).

\section{Results}

3.1. Serum Chemokine Levels. PAF levels were statistically higher in BP patients $(218.19+/-29.874)$ than healthy subjects $29.87+/-2.973(P=0.004981)$. No differences were found between $\mathrm{DH}$ patients and the control group $(P=0.614416)$, Figure 1.
MMP9 levels were significantly higher in BP patients (364.79 +/ -41.383$)$ and patients with dermatitis herpetiformis (243.10+/-77.110) compared to healthy subjects (52.61 $+/-0.779): P=0.000002$ and $P=0.029907$, respectively, Figure 1.

The chymase $(34.05+/-0.209$ versus $24.30+/-3.438$ versus $32.10+/-0.823)$, tryptase $(19.79+/-1.983$ versus 20.74 +/- 6.083 versus $19.33+/-3.231)$, IL-4 (68.66 +/- 6.653 versus $71.50+/-20.219$ versus $66.98+/-10.850)$, and TNF $\alpha$ $(57.26+/-1.263$ versus $63.57+/-3.318$ versus $62.11+/-2.558)$ levels were similar in BP and DH patients, as well as healthy controls, (Figure 1).

3.2. Expression of TNF $\alpha$ in Skin. Moderate expression of TNF $\alpha$ was found in inflammation cells, the basal keratinocytes, and blister fluid (Figure 2). TNF $\alpha$ expression was also observed in BP (17/27) and DH (9/14) perilesional skin (Figure 2). Immunohistochemistry revealed TNF $\alpha$ expression to be absent in the skin biopsies from control patients (Figure 2).

Morphometric analysis revealed that $\mathrm{TNF} \alpha$ expression was significantly higher in lesions than the surrounding skin: in $\mathrm{BP} 1.59 \pm 0.100$ versus $1.01 \pm 0.045(P=0.000005)$ and $\mathrm{DH} 1.39 \pm 0.069$ versus $0.62 \pm 0.050(P=0.004998)$ (Table 1) (Figure 3 ). Expression was significantly higher in $\mathrm{BP}$ and DH skin lesions versus control group (1.59 \pm 0.100 versus $0.16 \pm 0.017$ and $1.39 \pm 0.069$ versus $0.16 \pm 0.017$, resp., $P=0.000004$ and 0.007028$)$ and in $\mathrm{BP}$ perilesional skin versus control group $(1.01 \pm 0.045$ versus $0.16 \pm 0.017$, $P=0.0000001$ ) (Figure 4).

3.3. Expression of MMP9 in Skin. Moderate expression of MMP9 was found in inflammation cells in BP patients, as well as in the epidermal basal cells in DH patients (Figure 2). MMP9 expression was also observed in BP and DH patients in perilesional skin. Immunohistochemistry found MMP9 expression to be absent in the skin biopsies from control patients (Figure 2).

Morphometric analysis revealed that MMP9 expression was significantly higher in lesions than the surrounding skin in patients with $\mathrm{BP}(7.41 \pm 0.814$ versus $2.01 \pm 0.183, P=$ $0.000045)$ (Table 1$)$ and in those with $\mathrm{DH}(2.34 \pm 0.356$ versus $1.69 \pm 0.511)$. Expression was significantly higher in skin lesions in the BP group compared to the control group (7.41 \pm 0.814 versus $2.15 \pm 0.276)$. No differences were found between the expression of MMP9 in DH skin lesions versus perilesional skin $(P=0.128206)$ (Figures 3 and 4$)$.

\section{Discussion}

D'Auria et al. [17] have studied the correlation between the enzymes myeloperoxidase, a product specific for granulocytes, and tryptase, a proteolytic enzyme synthesized and released by mast cells, with the levels of various cytokines in the blister fluid. They note a positive correlation between the levels of tryptase, IL-8, and RANTES, showing high activity of cytokines in relation to influx of eosinophils. A few studies 

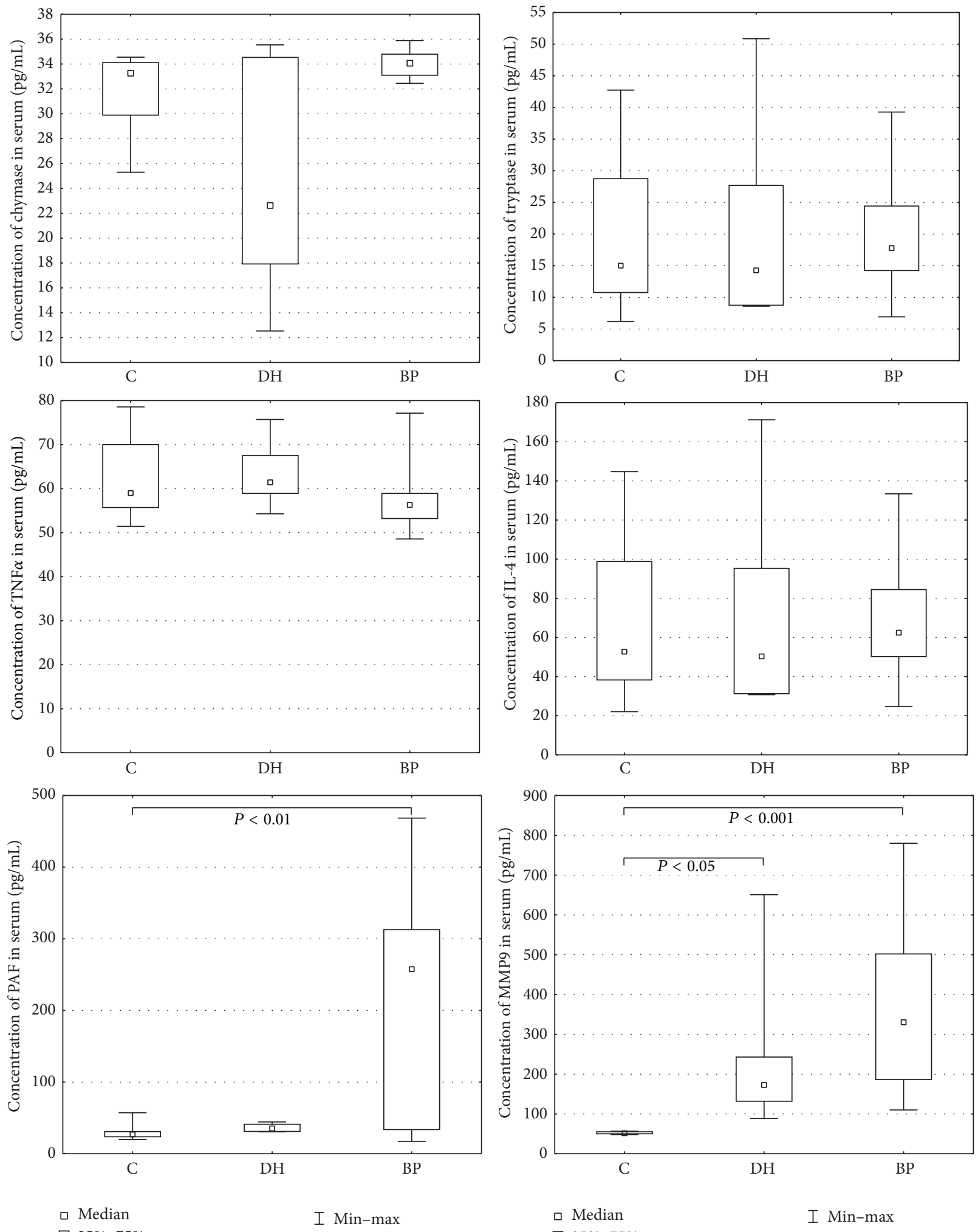

I Min-max

Median
$\square 25 \%-75 \%$

I Min-max

$\square 25 \%-75 \%$

FIGURE 1: Serum levels of examined mediators in BP, DH, and control groups. 


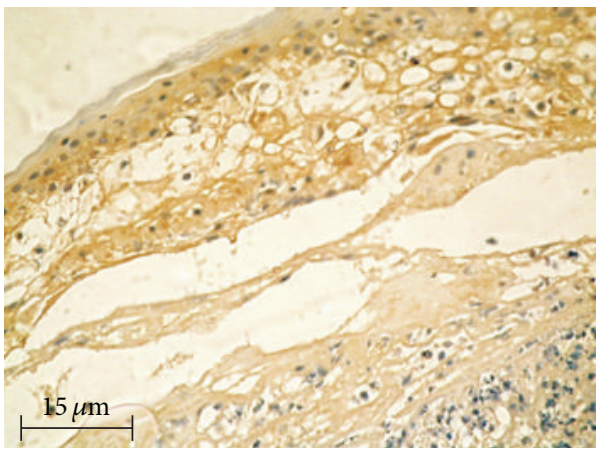

(a)

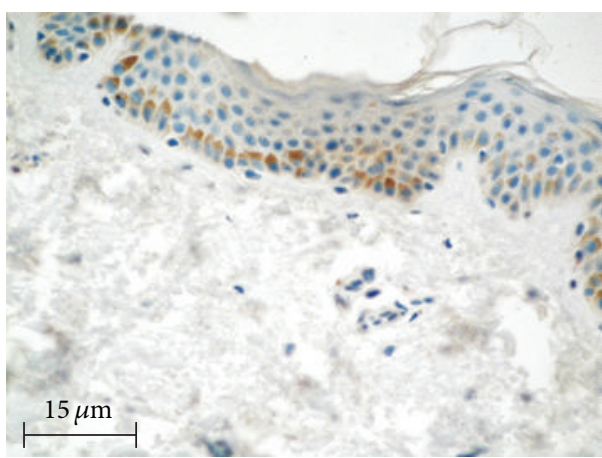

(c)

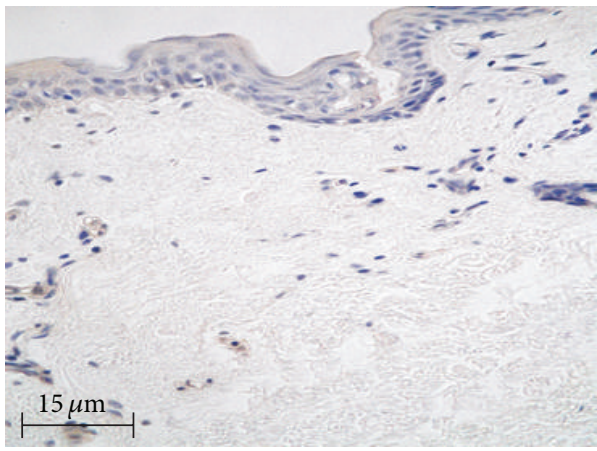

(e)

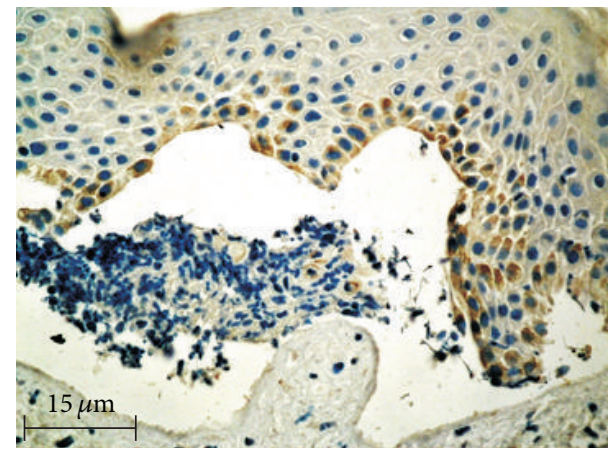

(b)

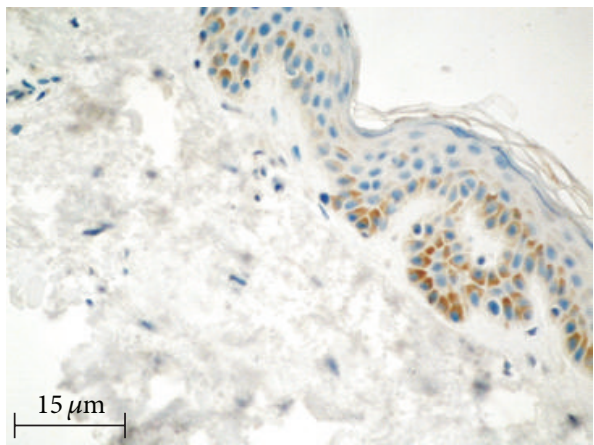

(d)

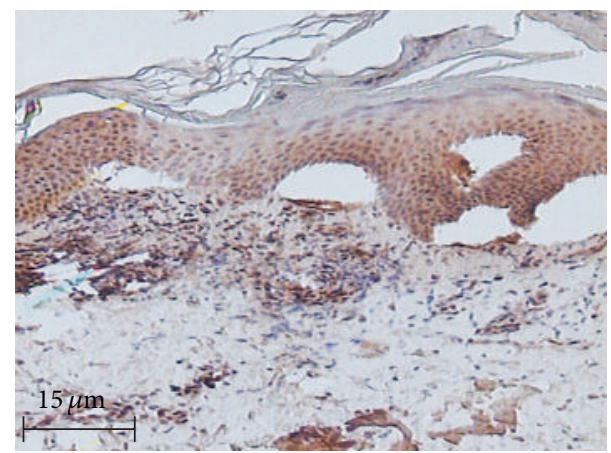

(f)

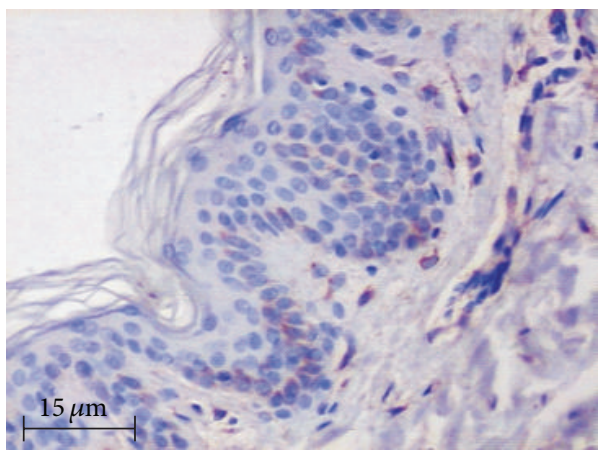

(g)

FIGURE 2: Immunoexpression of TNF $\alpha$ and MMP9 in epidermis and influx, 400x, immunohistochemistry. (a) Immunoexpression of TNF $\alpha$ in epidermis and influx, skin lesions (BP). (b) Immunoexpression of TNF $\alpha$ in epidermis, skin lesion (DH). (c) Immunoexpression of TNF $\alpha$ in epidermis, perilesional skin (BP). (d) Immunoexpression of TNF $\alpha$ in epidermis, perilesional skin (DH). (e) Negative immunoexpression of TNF $\alpha$, normal skin. (f) Immunoexpression of MMP9 in epidermis and influx, skin lesions (BP). (g) Almost negative immunoexpression of MMP9, normal skin. 
TABLE 1: The quantitative data of TNF $\alpha$ and MMP9 positive cells expressed in BP, DH, and control group (L), in lesion (S) and in the surrounding skin.

\begin{tabular}{|c|c|c|c|}
\hline $\mathrm{TNF} \alpha$ & $\mathrm{DH}$ & $\mathrm{BP}$ & Control \\
\hline \multicolumn{4}{|c|}{$\mathrm{L}$} \\
\hline Mean & 1.39 & 1.59 & 0.16 \\
\hline SEM & 0.069 & 0.100 & 0.017 \\
\hline Median & 1.38 & 1.48 & 0.15 \\
\hline Range & 0.50 & 1.52 & 0.20 \\
\hline \multicolumn{4}{|c|}{ S } \\
\hline Mean & 0.62 & 1.01 & 0.16 \\
\hline SEM & 0.050 & 0.045 & 0.017 \\
\hline Median & 0.64 & 0.94 & 0.15 \\
\hline Range & 0.35 & 0.87 & 0.20 \\
\hline MMP9 & $\mathrm{DH}$ & $\mathrm{BP}$ & Control \\
\hline \multicolumn{4}{|c|}{$\mathrm{L}$} \\
\hline Mean & 2.34 & 7.41 & 2.15 \\
\hline SEM & 0.356 & 0.814 & 0.276 \\
\hline Median & 2.51 & 7.66 & 2.68 \\
\hline Range & 2.52 & 14.57 & 2.63 \\
\hline \multicolumn{4}{|c|}{$\mathrm{S}$} \\
\hline Mean & 1.69 & 2.01 & 2.15 \\
\hline SEM & 0.511 & 0.183 & 0.276 \\
\hline Median & 1.09 & 1.81 & 2.68 \\
\hline Range & 3.64 & 3.76 & 2.63 \\
\hline
\end{tabular}

confirm that eosinophils are very important cells in the formation of infiltration in BP patients. Markers of eosinophils and neutrophils have an important influence on the cytokine network, as well as other factors, such as adhesion molecules, tissue factors, and chemokines. The elevated expression of mast cell mediators in skin lesions and serum suggests that activation of these cells in bullous diseases is also important.

It seems important to determine which of the mediators secreted from mast cells are involved in the development of skin lesions in blistering diseases. Mast cell markers include tryptase, chymase, IL-4, PAF, TNF $\alpha$, and the MMP9 enzyme.

As demonstrated by Heimbach et al. [18], the activation of complement and mast cell degranulation in a mouse model of $\mathrm{BP}$ is mediated by the C5a receptor. Recent studies confirm that these cells not only are involved in response to pathogens and in the mechanisms of allergy, but also are responsible for the development of neutrophilic infiltration [19].

Using an animal BP model, Chen et al. [20, 21] have also confirmed that mast cells are responsible for the influx of neutrophils and macrophages into tissues, which causes the destruction of the dermal-epidermal junction. Of the mast cell markers examined in the present study, significantly higher levels were found for PAF and MMP9 in patients with BP.

The mechanisms leading to mast cell activation and release of proteases in these diseases are poorly understood, but C3a and C5a anaphylatoxins, neuropeptides, and cytokines could be involved as well as numerous other proteins or peptides. The involvement of mast cells in inflammation and blister formation in subepidermal bullous diseases has been suggested, and since early skin lesions have an urticarial appearance, the mast cells are hypogranulated, and their granules are spread extracellularly and blister fluid contains increased histamine and tryptase levels. In addition, injection of the mast cell degranulator, compound $48 / 80$, into the skin of patients with dermatitis herpetiformis causes a DH-like bullous lesion in some cases [22]. The results suggest that mast cell proteases participate in the inflammatory reaction; however, their direct role in blister formation is not clear. It is possible that PAF and TNF $\alpha$ induce and maintain the blisters by continuously activating collagenolytic metalloproteinases and degrading fibronectin.

The expression of TNF $\alpha$ in bullous lesions in both diseases was also significantly elevated compared to healthy subjects. The significantly reduced expression of this cytokine observed in normal looking skin was also important, suggesting the participation of TNF $\alpha$ in the formation of inflammatory influx and blisters.

Our findings confirm the role of TNF $\alpha$ and mast cells in the formation of skin lesions through the development of neutrophilic infiltration and the subsequent activation of immune mechanisms. Mediators secreted by these cells may influence the early changes which have been described, such as urticarial wheals accompanied by strong itching, in the course of a BP.

The destruction of tissue in the disorders associated with the increased activity of matrix metalloproteinases is often the result of an imbalance between the activity of these enzymes and their inhibitors. Recently, MMPs have been reported to play a significant role in the pathogenesis of skin diseases, including blistering diseases [23]. Enzymes are thought to play a significant role in these diseases, in addition to a series of immunological phenomena which lead to the development of blisters.

Inflammatory cells are the main source of MMPs. Neutrophils forming influxes in the skin release the matrix and immunoglobulin-degrading enzymes [24, 25]. Cytokinesecreting lymphocytes are a cause of polynuclear cell influx and the activation of endopeptidases [24, 26].

Recent literature data shows that IgA-Ag complexes presented in the tissue in a course of different IgA-mediated diseases, also $\mathrm{DH}$, are responsible for tissue damage due to migration induction as well as granulocyte activation. This is why granulocytes are unable to destruct the complexes which lead to attract new multinuclear cells, sustain inflammation, and, as a consequence, cause tissue damage [27].

Our findings confirming the presence of TNF $\alpha$ and MMP9 in tissues from patients with $\mathrm{DH}$ confirm the role of IgA-Ag complexes mentioned above. Neutrophils are one of the major sources of those substances and act as important inflammatory cells. Most importantly, they possess the Fc $\alpha$ RI surface receptor, which allows them to link to IgA and activate the tissue damage process.

The autocrine and paracrine effects of cytokines on the inflammatory cells and keratinocytes appear to cause an imbalance between MMPs and their inhibitors. This phenomenon leads to changes in the architecture of the 

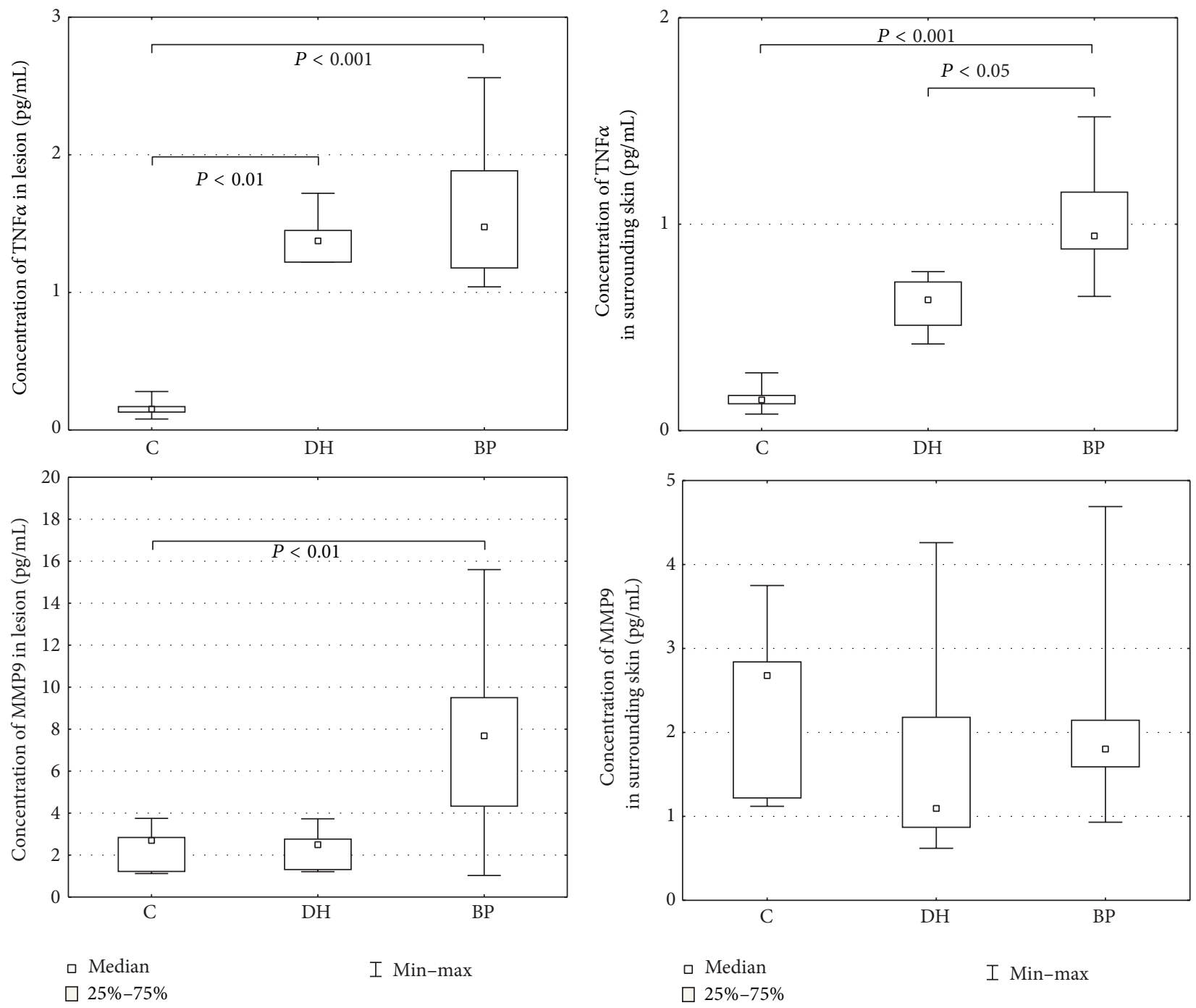

FIgURE 3: Morphometry of the immunoexpression of MMP9 and TNF $\alpha$, skin lesion.

extracellular matrix [26, 28, 29]. Some authors [29-31] have confirmed that collagenase and elastase are released mainly from inflammatory cells, regardless of the constitutive secretion of these enzymes by keratinocytes [32-34].

Previous reports confirm the increased activity of stromelysin 1 in skin lesions in patients with $\mathrm{DH}$. It is an enzyme which degrades the proteins of the basement membrane and activates procolagenasis. No increased expression of other MMPs such as matrilysin has been observed, although they may potentially cause proteolysis of basement membrane proteins such as entactin and type IV collagen [35]. In our study, MMP9 expression was found not only in basal keratinocytes but also in all other layers of the epidermis in patients with BP. Metalloproteinase 9 probably contributes to the formation of blisters by the degradation of the anchoring fibres [34].

Our experiences confirm those reports. The high expression of MMP9 was observed in basal keratinocytes, in areas of intense neutrophilic infiltration, and in blister fluid. However, the results show the possibility of stimulating the production of metalloproteinases by other layers of the epidermis. MMP9 is probably the primary element responsible for the formation of lesions in the course of BP [32]. Fluid extracted from the newly formed blister may be a good material for the assessment of the activity of metalloproteinase in skin lesions.

Recent reports suggest that collagen XVII and collagen VII, which are the basis of anchoring fibers, undergo proteolysis under the influence of a specific group of metalloproteinases. In murine models of bullous pemphigoid, Verraes et al. [34] assess the participation of neutrophil elastase and MMP9 in the formation of blisters through the proteolytic degradation of the BP antigen 180 . Both of these enzymes have been found to be present in specimens from both lesions and blister fluid [34]. The results of these studies have not yet been confirmed in in vivo experiments, where the main infiltration cells, eosinophils, do not have the ability to secrete this type of metalloproteinase.

Based on the obtained results, it can be concluded that the increased activity of matrix metalloproteinase 9 and the consequent imbalance between the groups of enzymes 

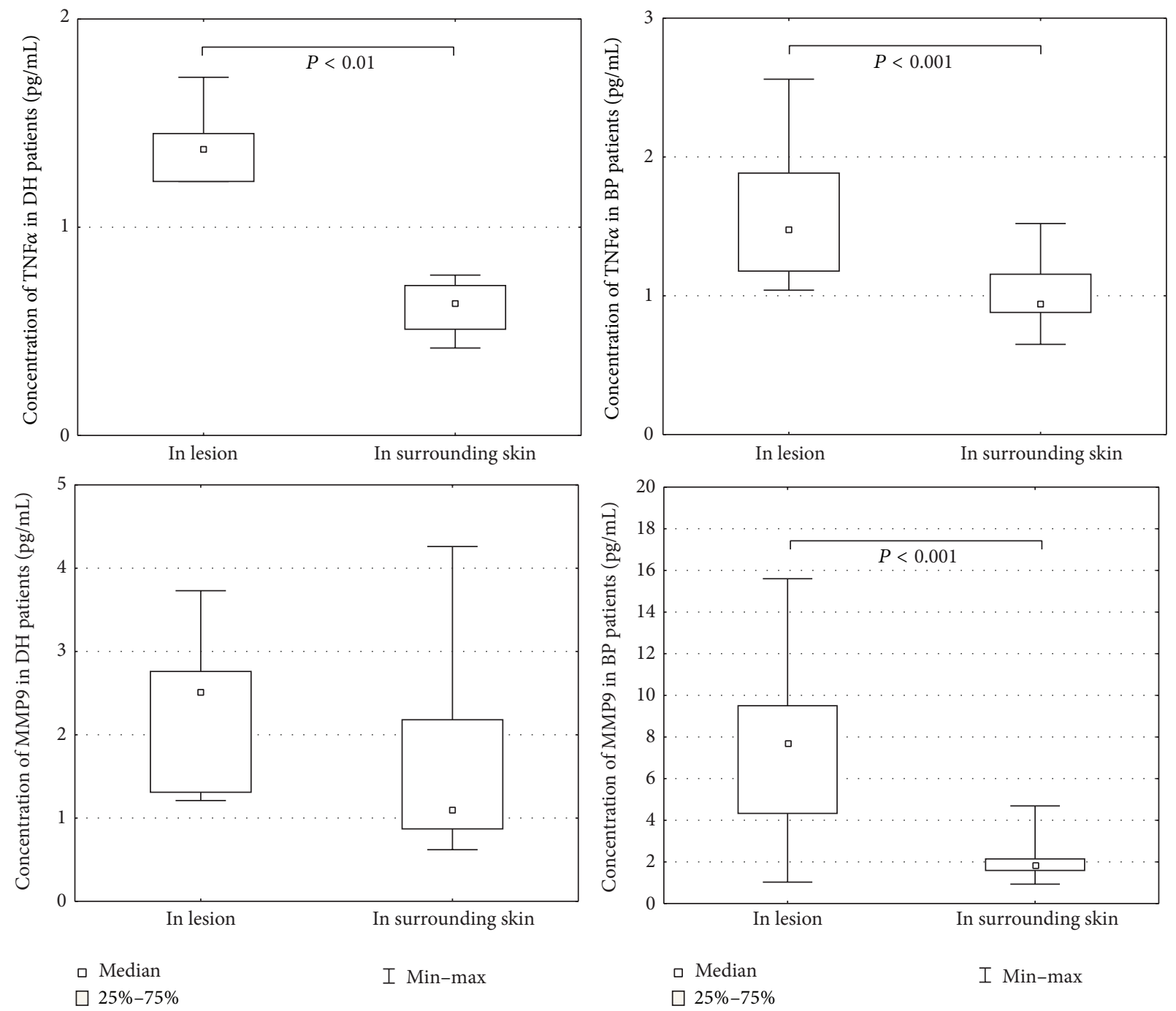

FIGURE 4: Morphometry of the immunoexpression of MMP9 and TNF $\alpha$, perilesional skin.

are responsible for tissue destruction in the course of BP. Considering the increasing number of studies concerning the participation of MMPs in the pathology of skin diseases, research regarding the therapeutic use of MMP inhibitors can be expected in the near future.

The findings of the present study demonstrate increased expression of TNF $\alpha$ in skin lesions, both in the case of bullous pemphigoid and in dermatitis herpetiformis. This can activate the production of other inflammatory mediators. Elevated PAF and MMP9 levels in the sera of patients may indicate the activation of mast cells in the process of blister formation in these diseases. In the present study, we investigated the relative contribution of mediators of mast cells in the immunopathogenesis of BP and DH skin lesions. We conclude that mast cells are active participants in events that mediate tissue damage in autoimmune disease. Diseaseassociated increases in mast cell numbers accompanied by mast cell degranulation and elaboration of numerous mast cell mediators at sites of inflammation are commonly observed in many human autoimmune diseases, such as multiple sclerosis and rheumatoid arthritis. In animal models, treatment with mast cell stabilizing drugs or mast cell ablation can result in diminished disease [35].

\section{Conflict of Interests}

The authors declare that there is no conflict of interests regarding the publication of this paper.

\section{Acknowledgments}

The study was funded by Medical University of Lodz research projects no. 503/1-152-01/503-01 and The Polish Science Committee Grant no. 4746/B/PO1/2009/37.

\section{References}

[1] S. Kárpáti, "Dermatitis herpetiformis: close to unravelling a disease," Journal of Dermatological Science, vol. 34, no. 2, pp. 8390, 2004 . 
[2] M. Sárdy, S. Kárpáti, B. Merkl, M. Paulsson, and N. Smyth, "Epidermal transglutaminase (TGase 3 ) is the autoantigen of dermatitis herpetiformis," The Journal of Experimental Medicine, vol. 195, no. 6, pp. 747-757, 2002.

[3] W. Dieterich, E. Laag, L. Bruckner-Tuderman et al., "Antibodies to tissue transglutaminase as serologic markers in patients with dermatitis herpetiformis," Journal of Investigative Dermatology, vol. 113, no. 1, pp. 133-136, 1999.

[4] J. D. Hendrix, K. L. Mangum, J. J. Zone, and W. R. Gammon, "Cutaneous IgA deposits in bullous diseases function as ligands to mediate adherence of activated neutrophils," Journal of Investigative Dermatology, vol. 94, no. 5, pp. 667-672, 1990.

[5] M. V. Dahl, R. J. Falk, R. Carpenter, and A. F. Michael, "Membrane attack complex of complement in dermatitis herpetiformis," Archives of Dermatology, vol. 121, no. 1, pp. 70-72, 1985.

[6] K. Airola, M. Vaalamo, T. Reunala, and U. K. Saarialho-Kere, "Enhanced expression of interstitial collagenase, stromelysin1 , and urokinase plasminogen activator in lesions of dermatitis herpetiformis," Journal of Investigative Dermatology, vol. 105, no. 2, pp. 184-189, 1995.

[7] R. F. Ghohestani, J. Novotney, M. Chaudhary, and R. S. Agah, "Bullous pemphigoid: from the bedside to the research laboratory," Clinics in Dermatology, vol. 19, no. 6, pp. 690-696, 2001.

[8] J. R. Stanley, "Cell adhesion molecules as targets of autoantibodies in pemphigus and pemphigoid, bullous diseases due to defective epidermal cell adhesion," Advances in Immunology, vol. 53, pp. 291-326, 1993.

[9] R. E. Jordon, E. H. Beutner, E. Witebsky, G. Blumental, W. L. Hale, and W. F. Lever, "Basement zone antibodies in bullous pemphigoid," Journal of the American Medical Association, vol. 200, no. 9, pp. 751-756, 1967.

[10] E. Schmidt, S. Reimer, N. Kruse et al., "Autoantibodies to BP180 associated with bullous pemphigoid release interleukin- 6 and interleukin-8 from cultured human keratinocytes," Journal of Investigative Dermatology, vol. 115, no. 5, pp. 842-848, 2000.

[11] S. A. Grando, B. T. Glukhenky, G. N. Drannik, E. V. Epshtein, A. P. Kostromin, and T. A. Korostash, "Mediators of inflammation in blister fluids from patients with pemphigus vulgaris and bullous pemphigoid," Archives of Dermatology, vol. 125, no. 7, pp. 925-930, 1989.

[12] M. Baggioloni, "Chemokines in pathology and medicine," Journal of Internal Medicine, vol. 250, no. 2, pp. 91-104, 2001.

[13] M. M. Wong and E. N. Fish, "Chemokines: attractive mediators of the immune response," Seminars in Immunology, vol. 15, no. 1, pp. 5-14, 2003.

[14] B. U. Wintroub, M. C. Mihm, E. J. Goetzl, N. A. Soter, and K. F. Austen, "Morphologic and functional evidence for release of mast-cell products in bullous pemphigoid," The New England Journal of Medicine, vol. 298, no. 8, pp. 417-421, 1978.

[15] A. B. Ackerman, N. Chongchitnant, J. Sanchex et al., Histologic Diagnosis of Inflammatory Skin Disease: A Algorithmic Method Based on Pattern Analysis, Williams \& Wilkins, Baltimore, Md, USA, 2nd edition, 1997.

[16] E. R. Weibel, "Point counting methods", in Stereological Methods, E. R. Weibel, Ed., vol. 1, pp. 101-159, Academic Press, London, UK, 1979.

[17] L. D’Auria, M. Pietravalle, P. Cordiali-Fei, and F. Ameglio, "Increased tryptase and myeloperoxidase levels in blister fluids of patients with bullous pemphigoid: correlations with cytokines, adhesion molecules and anti-basement membrane zone antibodies," Experimental Dermatology, vol. 9, no. 2, pp. 131-137, 2000 .
[18] L. Heimbach, Z. Li, P. Berkowitz et al., "The C5a receptor on mast cells is critical for the autoimmune skin-blistering disease bullous pemphigoid," The Journal of Biological Chemistry, vol. 286, no. 17, pp. 15003-15009, 2011.

[19] B. A. Walker, M. A. Jacobson, D. A. Knight et al., "Adenosine A3 receptor expression and function in eosinophils," American Journal of Respiratory Cell and Molecular Biology, vol. 16, no. 5, pp. 531-537, 1997.

[20] R. Chen, J. A. Fairley, M.-L. Zhao et al., "Macrophages, but not $\mathrm{T}$ and $\mathrm{B}$ lymphocytes, are critical for subepidermal blister formation in experimental bullous pemphigoid: macrophagemediated neutrophil infiltration depends on mast cell activation," Journal of Immunology, vol. 169, no. 7, pp. 3987-3992, 2002.

[21] R. Chen, G. Ning, M.-L. Zhao et al., "Mast cells play a key role in neutrophil recruitment in experimental bullous pemphigoid," The Journal of Clinical Investigation, vol. 108, no. 8, pp. 1151-1158, 2001.

[22] K. Brockow, D. Abeck, K. Hermann, and J. Ring, "Tryptase concentration in skin blister fluid from patients with bullous skin conditions," Archives of Dermatological Research, vol. 288, no. 12, pp. 771-773, 1996.

[23] Y. Niimi, R. Pawankar, and S. Kawana, "Increased expression of matrix metalloproteinase-2, matrix metalloproteinase- 9 and matrix metalloproteinase-13 in lesional skin of bullous pemphigoid," International Archives of Allergy and Immunology, vol. 139, no. 2, pp. 104-113, 2006.

[24] H. Nagase, "Activation mechanisms of matrix metalloproteinases," Biological Chemistry, vol. 378, no. 3-4, pp. 151-160, 1997.

[25] D. Reinhardt, H. H. Sigusch, J. Henße, S. C. Tyagi, R. Körfer, and H. R. Figulla, "Cardiac remodelling in end stage heart failure: upregulation of matrix metalloproteinase (MMP) irrespective of the underlying disease, and evidence for a direct inhibitory effect of ACE inhibitors on MMP," Heart, vol. 88, no. 5, pp. 525530, 2002.

[26] J. J. Reynolds, "Collagenases and tissues inhibitors of metalloproteinases: functional balance in tissue degradation," Oral Diseases, vol. 2, no. 1, pp. 70-76, 1996.

[27] L. P. van der Steen, J. E. Bakema, A. Sesarman et al., "Blocking Fc $\alpha$ receptor I on granulocytes prevents tissue damage induced by IgA autoantibodies," The Journal of Immunology, vol. 189, no. 4, pp. 1594-1601, 2012.

[28] J. J. Reynolds and M. C. Meikle, "The functional balance of metalloproteinases and inhibitors in tissue degradation: relevance to oral pathologies," Journal of the Royal College of Surgeons of Edinburgh, vol. 42, no. 3, pp. 154-160, 1997.

[29] K. J. Leco, R. Khokha, N. Pavloff, S. P. Hawkes, and D. R. Edwards, "Tissue inhibitor of metalloproteinases-3 (TIMP-3) is an extracellular matrix-associated protein with a distinctive pattern of expression in mouse cells and tissues," The Journal of Biological Chemistry, vol. 269, no. 12, pp. 9352-9360, 1994.

[30] M. Larry and W. Corcoran, "Regulation of monocyte/macrophage metalloproteinase production by cytokines," Journal of Periodontology, vol. 64, no. 5, pp. 467-473, 1993.

[31] L. S. Lohmander, L. A. Hoerrner, and M. W. Lark, "Metalloproteinases, tissue inhibitor, and proteoglycan fragments in knee synovial fluid in human osteoarthritis," Arthritis and Rheumatism, vol. 36, no. 2, pp. 181-189, 1993.

[32] A. I. Oikarinen, J. J. Zone, A. R. Ahmed, U. Kiistala, and J. Uitto, "Demonstration of collagenase and elastase activities in the blister fluids from bullous skin diseases. Comparison between 
dermatitis herpetiformis and bullous pemphigoid," Journal of Investigative Dermatology, vol. 81, no. 3, pp. 261-266, 1983.

[33] H. G. Welgus, E. A. Bauer, and G. P. Stricklin, "Elevated levels of human collagenase inhibitor in blister fluids of diverse etiology," Journal of Investigative Dermatology, vol. 87, no. 5, pp. 592-596, 1986.

[34] S. Verraes, W. Hornebeck, M. Polette, L. Borradori, and P. Bernard, "Respective contribution of neutrophil elastase and matrix metalloproteinase 9 in the degradation of BP180 (type XVII collagen) in human bullous pemphigoid," Journal of Investigative Dermatology, vol. 117, no. 5, pp. 1091-1096, 2001.

[35] M. A. Brown and J. K. Hatfield, "Mast cells are important modifiers of autoimmune disease: with so much evidence, why is there still controversy?" Frontiers in Immunology, vol. 7, no. 3, article 147, 2012. 


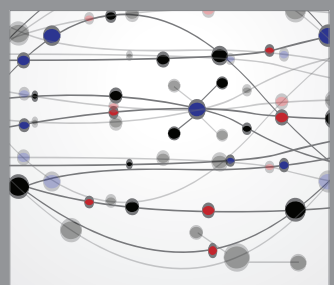

The Scientific World Journal
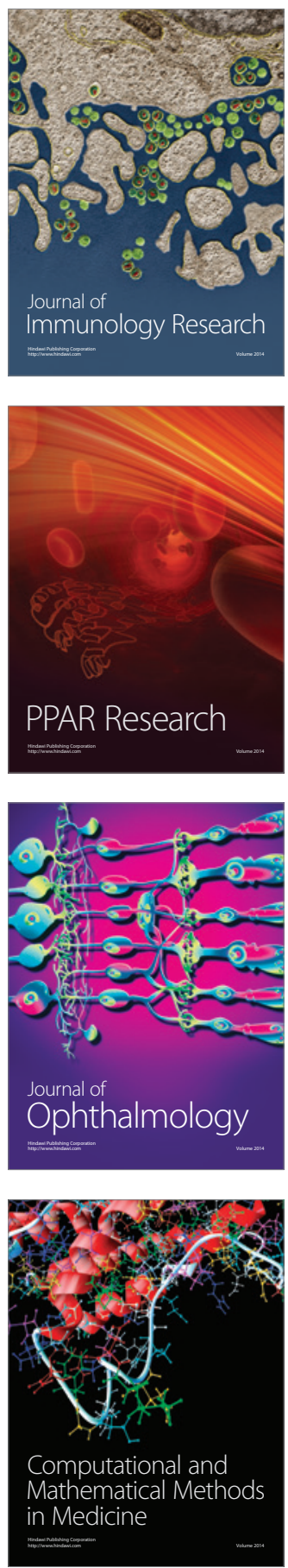

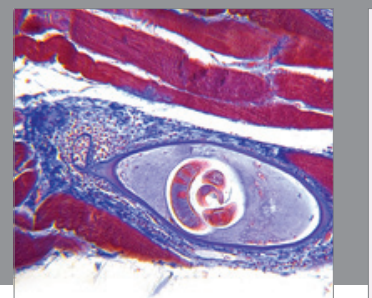

Gastroenterology

Research and Practice
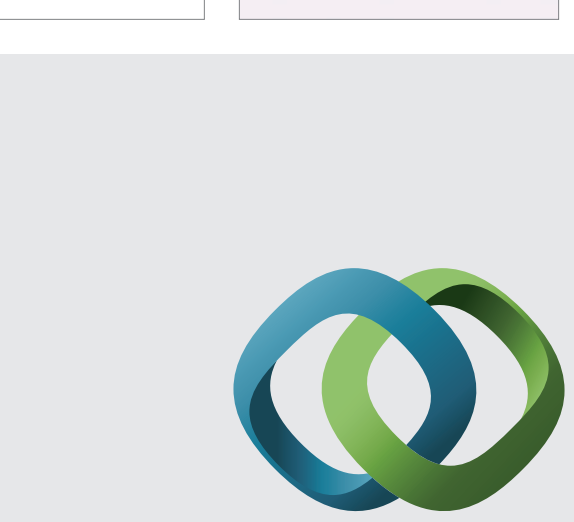

\section{Hindawi}

Submit your manuscripts at

http://www.hindawi.com
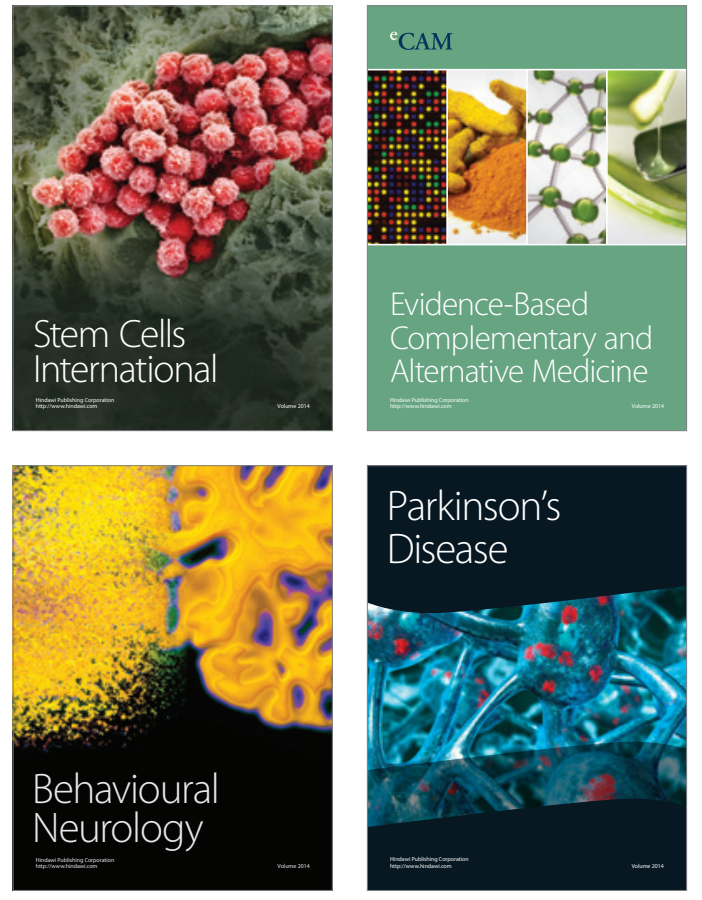
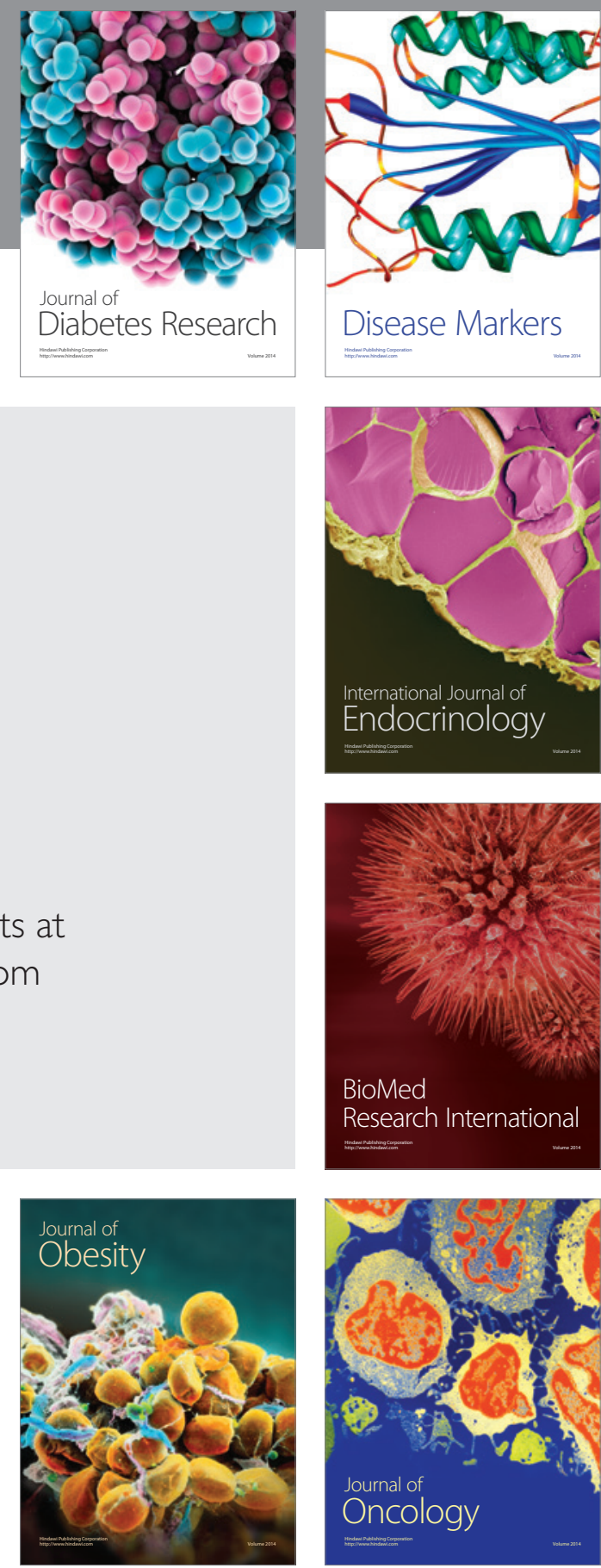

Disease Markers
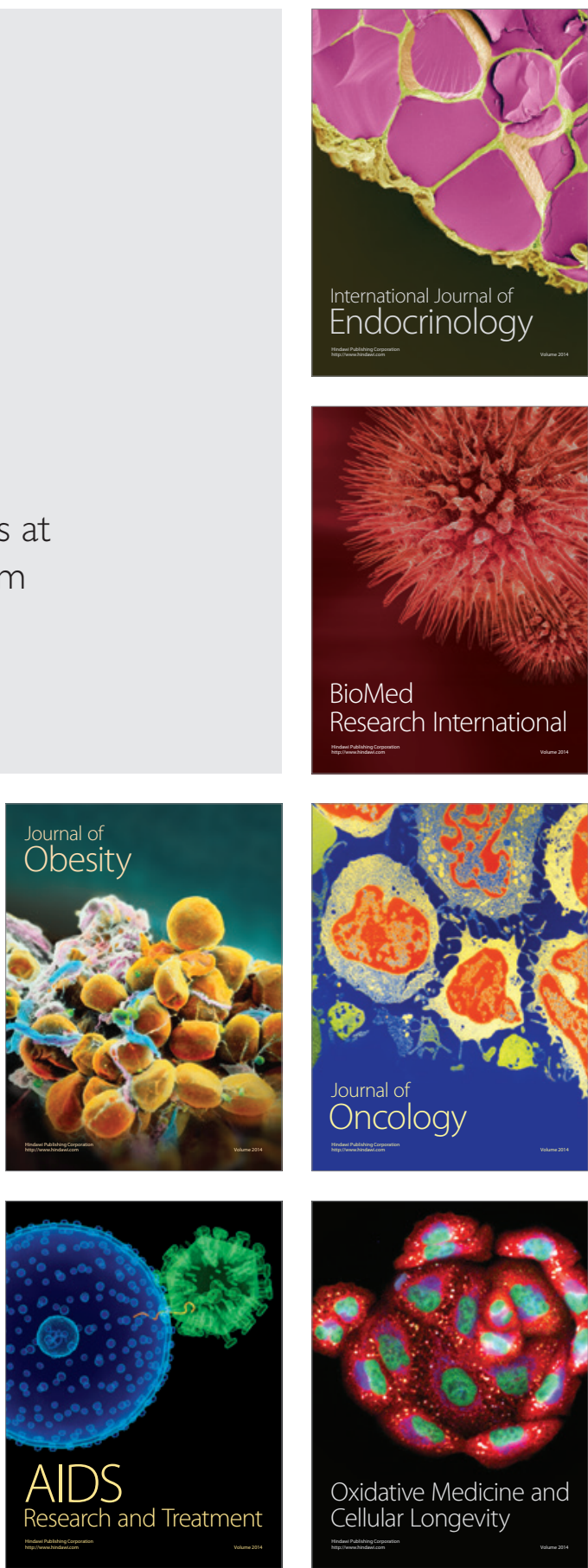